\title{
Medical Record
}

National Cancer Institute

\section{Source}

National Cancer Institute. Medical Record. NCI Thesaurus. Code C45258.

A chronological written account of a patient's examination and treatment that includes the patient's medical history and complaints, the physician's physical findings, the results of diagnostic tests and procedures, and medications and therapeutic procedures. 